\title{
A comparison of the growth and dry matter distribution of couch (Elymus repens (L.) Gould) and perennial ryegrass (Lolium perenne L.) at different levels of mineral nutrition
}

\section{J. H. Neuteboom ${ }^{1}$ and W. Cramer}

'Department of Field Crops and Grassland Science, Agricultural University, Haarweg 333, 6709 RZ Wageningen, Netherlands

Received 4 June 1985; accepted 1 October 1985

Key words: couch, perennial ryegrass, shoot growth, root growth, rhizome growth, dry matter distribution, mineral nutrition.

\section{Summary}

Seedlings of couch (Elymus repens (L.) Gould) and perennial ryegrass (Lolium perenne L.) were grown outdoors in soil-filled pots. In one treatment soil fertility was kept at a high level by applying a complete nutrient solution as fortnightly gifts of consecutively $15,15,25,25,30$ and 30 meq nitrogen per pot. The second treatment received gifts only one-third of those in the first treatment, and the third treatment received none.

Couch and perennial ryegrass had similar total relative growth rates, but during the period of strong rhizome growth of couch, the relative growth rates of the couch shoots and roots - especialy the latter - were lower than those of the perennial ryegrass. The lower growth rate of the couch roots was particularly marked at the lower levels of nutrient supply. Nutrient supply strongly promoted rhizome branching.

Couch in grassland might be less competitive than perennial ryegrass for the available minerals and water because of its lower root production. The strong effect of mineral nutrition on rhizome branching may explain why couch can so easily colonize open patches in intensively used grasslands.

\section{Introduction}

Much is known about the effect of various external factors on the root/shoot ratio of plant species. However, most of these studies concern non-rhizomatous species where an easy distinction can be made between roots and aerial shoots. Several workers (e.g. Troughton, 1977) have concluded that a particular plant at a given age has a definite root/shoot ratio in a specific environment. This ratio results from the relative growth rates of the roots and the shoots, which might be determined by 
competition between these organs for minerals and water taken up by the roots and for carbohydrates photosynthesized in the shoots. Brouwer (1963) termed the relationship between the growth of roots and shoots a functional equilibrium, which changes if the environmental factors change. However, the root/shoot ratio may also be affected by the exchange of growth substances between the roots and the shoots, and certainly depends on the developmental stage of the plant.

The peculiarity of rhizomes is that as underground stems they do not have a welldefined function within the plant in the supply of some material or metabolite. They mainly act as consumers and conversers of carbohydrates, minerals and water and will therefore compete for them together with the roots and shoots. This raises the question of how rhizome formation relates to the growth of roots and shoots under changing environmental conditions.

This was studied with perennial ryegrass (Lolium perenne $\mathrm{L}$.), which has no rhizomes, and couch (Agropyron repens (L.) Beauv., = Elymus repens (L.) Gould), which does have rhizomes. These species were also chosen because couch can increase strongly in intensively utilized perennial ryegrass grasslands. This increase has been supposed by some to be directly related to the high applications of nitrogen. However, couch does not increase in all cases of high nitrogen applications, and to explain this several authors (Boxem, 1966; Wetzel, 1966; Hoogerkamp, $1975 \mathrm{a}, \mathrm{b})$ have pointed out that in grassland other factors change as a result of the improved nitrogen fertilization and that these might facilitate the spread of couch. A higher nitrogen fertilization will enable higher stocking rates, which result in more sward damage from trampling, dung and urine patches during the grazing period, and in more organic manure in winter, while also increasing the risk of late harvesting. All these factors might weaken perennial ryegrass especially, thereby causing an open sward. If the harvest is left until late, the perennial ryegrass might also be crowded out of a dense couch stand because of competition for light (Neuteboom, 1981).

Although this indirect relationship between the increase in couch in intensively used grassland and high nitrogen fertilizations is generally accepted, it is not known how the two species react individually to different applications of nitrogen. This was investigated in a pot experiment.

\section{Materials and methods}

On 4 June 1979, 4-week-old seedlings of a mixed couch population and of the perennial ryegrass variety Cropper (Anonymous, 1981) were planted outdoors in 5litre pots filled with a fairly fertile soil, one plant per pot. In one treatment (N1) soil fertility was kept at a high level by giving a complete nutrient solution in fortnightly gifts of consecutively $15,15,25,25,30$ and $30 \mathrm{meq} \mathrm{N}$. In a second treatment $(\mathrm{N} 1 / 3)$ only one-third of these amounts were applied and in a third treatment (N0) no nutrient solution was applied. During the experiment the plants were given sufficient water.

Plants were harvested after 2, 5, 8 and 12 weeks of undisturbed growth, i.e. on 18 June, 9 and 30 July and 27 August, 5 couch and 5 perennial ryegrass plants per har- 
vest date. After the shoots, rhizomes and rhizome branches had been counted and dried for 24 hours at $70^{\circ} \mathrm{C}$, the dry weights of the shoots, roots and rhizomes of each plant were determined. All these components were analysed for total nitrogen and water-soluble carbohydrates. Water-soluble carbohydrates were colorimetrically determined with an automatic analysing device using ferrycyanide. Nitrogen was also colorimetrically determined with salicylate and hypochlorite.

\section{Results}

\section{General species differences}

Couch forms rhizomes but it also differs from perennial ryegrass because it exhibits continuous stem elongation, even during vegetative growth. Perennial ryegrass can generally form a much denser sward (Neuteboom, 1981), although it has a lower mean shoot weight. These differences in tillering and mean shoot weight are illustrated in Table 1, where for couch a distinction has been made between parent plants that developed by tillering and daughter plants that originated from rhizomes. The rhizomes easily grew along the inside of the pot, and therefore the formation of daughter plants was unlikely to have resulted from a restriction of the horizontal growth of the rhizomes. Despite the late planting in spring the couch plants developed inflorescences, and since all plants were raised from seeds this suggests that couch has no clear requirement for vernalization or for short-day induction. The perennial ryegrass plants remained vegetative.

Effects of mineral nutrition: The couch and the perennial ryegrass plants did not differ in total plant dry weights, nor in relative growth rates in treatment N0 (Table 2, Fig. 1). With the higher yields at the higher levels of nutrient supply (N1/3 and N1) the perennial ryegrass plants were up to $20 \%$ more productive than the couch plants; the $\mathrm{N}$ effect on yield did not become clear until the second harvest date when the nutrient supply in the NO treatment had apparently become exhausted. However, after the first harvest date, when it was found that couch had developed many rhizomes, the couch plants lagged strongly behind the perennial ryegrass plants in their root and shoot growth (Fig. 2; Table 2). This is also illustrated by the mean relative growth rates of the roots and the shoots of the couch and the perennial ryegrass plants that were calculated for the periods between the 4th (last) and the

Table 1. Mean shoot numbers and mean shoot weights of the couch (Ely) and perennial ryegrass plants (Lp) at the last harvest date (N1 treatment).

\begin{tabular}{|c|c|c|c|c|c|}
\hline \multicolumn{4}{|c|}{ Shoot number } & \multicolumn{2}{|c|}{ Mean shoot weight $(\mathrm{mg})$} \\
\hline \multicolumn{3}{|l|}{ Ely } & \multirow[t]{2}{*}{$\mathrm{Lp}$} & \multirow[t]{2}{*}{ Ely } & \multirow[t]{2}{*}{ Lp } \\
\hline $\begin{array}{l}\text { parent } \\
\text { plant }\end{array}$ & $\begin{array}{l}\text { daughter } \\
\text { plants from } \\
\text { rhizomes }\end{array}$ & total & & & \\
\hline 76 & 46 & 122 & 431 & 370 & 181 \\
\hline
\end{tabular}


Table 2. Total plant dry weights $(\mathrm{g})$ and dry weights of the shoots, roots and rhizomes of the couch plants (Ely) and of the perennial ryegrass plants (Lp) at the third and the last harvest dates.

\begin{tabular}{|c|c|c|c|c|c|c|c|c|c|}
\hline & & \multicolumn{4}{|c|}{30 July } & \multicolumn{4}{|c|}{27 August } \\
\hline & & $\begin{array}{l}\text { total } \\
\text { plant }\end{array}$ & shoot & root & rhizome & $\begin{array}{l}\text { total } \\
\text { plant }\end{array}$ & shoot & root & rhizome \\
\hline \multirow[t]{2}{*}{ N0 } & Lp & 19.9 & 10.3 & 9.6 & & 24.8 & 11.3 & 13.5 & \\
\hline & Ely & 19.3 & 6.7 & 3.4 & 9.1 & 26.9 & 9.6 & 6.1 & 11.2 \\
\hline \multirow[t]{2}{*}{$\mathrm{N} 1 / 3$} & $\mathrm{Lp}$ & 46.1 & 30.5 & 15.6 & & 78.6 & 42.1 & 41.6 & \\
\hline & Ely & 32.5 & 18.1 & 6.6 & 7.9 & 63.2 & 22.3 & 9.7 & 31.2 \\
\hline \multirow[t]{2}{*}{ N1 } & Lp & 58.3 & 41.7 & 16.6 & & 119.6 & 78.0 & 41.6 & \\
\hline & Ely & 50.9 & 32.3 & 9.5 & 9.1 & 97.4 & 45.2 & 19.3 & 32.9 \\
\hline
\end{tabular}

first harvest dates and between the 3rd and the first harvest dates (Table 3). Nutrient supply had no effect on the relative growth rate of the rhizomes, except that after the third harvest the $\mathrm{N} 0$ treatment lagged behind. The rhizomes continued to grow with higher relative growth rates than the roots and shoots (Fig. 2; Table 3). The experiments done by Williams (1971) and Pooswang et al. (1972) also indicate that couch rhizomes can have higher relative growth rates than the roots and shoots.

At the 3rd harvest date there were more rhizome branches in treatments $\mathrm{N} 1 / 3$ and $\mathrm{N} 1$ than in treatment $\mathrm{N} 0$, whereas at the last harvest date there were more branches in the N1 treatment than in the N1/3 treatment (Table 4). These branches did not yet contribute to a higher rhizome dry weight (Fig. 2) because most of them were very short. The greater number of rhizome branches at the last harvest date in treatment N1 suggests that in this treatment the rhizome dry weight would also have eventually been higher than in both other treatments. The fact that at the $3 \mathrm{rd}$

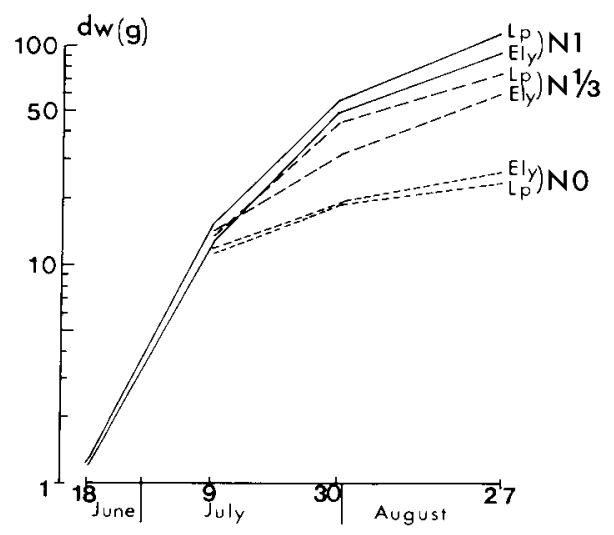

Fig. 1. Total plant dry weights of the couch (Ely) and perennial ryegrass plants (Lp) at the 4 consecutive harvest dates. Data according to the 3 levels of mineral supply (N0, N1/3, N1). 

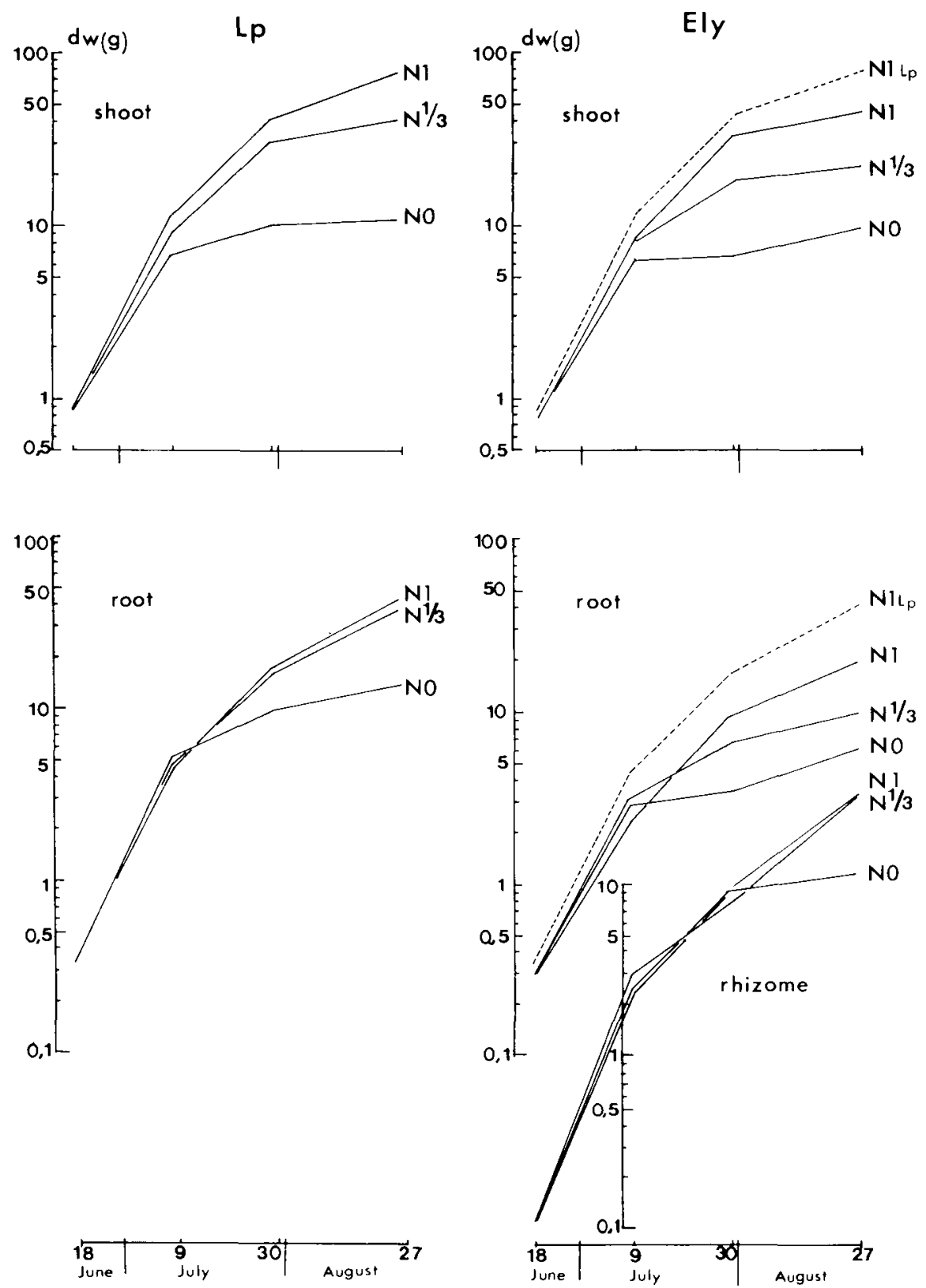

Fig. 2. Root. shoot and rhizome dry weights of the couch plants (Ely), and root and shoot dry weights of the perennial ryegrass plants $(\mathrm{Lp})$. 


\section{J. H. NEUTEBOOM AND W. CRAMER}

Table 3. Mean relative growth rates $\left(\overline{\mathrm{R}}, \mathrm{g} \mathrm{g}^{-1}\right.$ week $\left.^{-1}\right)$ between the $3 \mathrm{rd}$ and the first harvest dates, and between the last (4th) and the first harvest dates, of the couch and the perennial ryegrass plants.

\begin{tabular}{|c|c|c|c|c|c|c|c|c|c|}
\hline & & \multicolumn{4}{|c|}{$\overline{\mathrm{R}} 18 / 6-30 / 7$} & \multicolumn{4}{|c|}{$\overline{\mathrm{R}} 18 / 6-27 / 8$} \\
\hline & & $\begin{array}{l}\text { total } \\
\text { plant }\end{array}$ & shoot & root & rhizome & $\begin{array}{l}\text { total } \\
\text { plant }\end{array}$ & shoot & root & rhizome \\
\hline \multirow[t]{2}{*}{ No } & Lp & 0.47 & 0.42 & 0.56 & & 0.31 & 0.26 & 0.37 & \\
\hline & Ely & 0.46 & 0.34 & 0.41 & 0.82 & 0.31 & 0.24 & 0.30 & 0.51 \\
\hline \multirow[t]{2}{*}{$\mathrm{N} 1 / 3$} & $\mathrm{Lp}$ & 0.61 & 0.60 & 0.64 & & 0.42 & 0.39 & 0.47 & \\
\hline & Ely & 0.54 & 0.50 & 0.39 & 0.79 & 0.39 & 0.32 & 0.35 & 0.61 \\
\hline \multirow[t]{2}{*}{$\mathrm{N} 1$} & Lp & 0.65 & 0.65 & 0.65 & & 0.46 & 0.46 & 0.48 & \\
\hline & Ely & 0.62 & 0.60 & 0.58 & 0.82 & 0.44 & 0.40 & 0.42 & 0.62 \\
\hline
\end{tabular}

and at the last harvest dates many of the rhizome branches were very short, suggests that these branches had been initiated simultaneously, possibly as a consequence of the sudden fall off of apical dominance from the rhizome apex. At the last harvest date, at all three levels of the mineral supply in all couch plants the length of the longest rhizome was similar (ca. $80 \mathrm{~cm}$ ), as was the diameter: this implies that mineral nutrition primarily affected rhizome production via its effect on the number of rhizomes and rhizome branches.

Couch and perennial ryegrass had comparable amounts of water-soluble carbohydrates (WSC) and comparable WSC concentrations on a whole-plant basis (Table 5). However, with couch most of these carbohydrates were in the rhizomes (see the high WSC concentrations of its rhizomes) whereas the shoots of perennial ryegrass had clearly higher WSC concentrations than those of couch (Table 5). At the $3 \mathrm{rd}$ and last harvests, perennial ryegrass had on average $77 \%$ of the total amount of WSC in its shoots, whereas couch had only $32 \%$ in its shoots and $50 \%$ in its rhizomes (Fig. 3a). At the last harvest date the rhizomes of couch in the N1 treatment had a relatively low WSC concentration and a relatively high nitrogen concentration (Table 5). This might have been related to a high meristem activity induced by the initiation of the many rhizome branches. Turner (1968) also found that rhizomes can have remarkably high WSC concentrations.

Table 4. Number of main rhizomes and number of rhizome branches of the couch plants at 30 July (3rd harvest) and 27 August (4th harvest).

\begin{tabular}{|c|c|c|c|c|c|c|}
\hline & \multicolumn{3}{|c|}{ Main rhizomes } & \multicolumn{3}{|c|}{ Rhizome branches } \\
\hline & No & $\mathrm{N} 1 / 3$ & N1 & No & $\mathrm{N} 1 / 3$ & N1 \\
\hline 30 July & 7 & 15 & 11 & 17 & 28 & 26 \\
\hline 27 August & 10 & 13 & 14 & 7 & 43 & 97 \\
\hline
\end{tabular}


GROWTH AND DRY MATTER DISTRIBUTION OF COUCH AND RYEGRASS

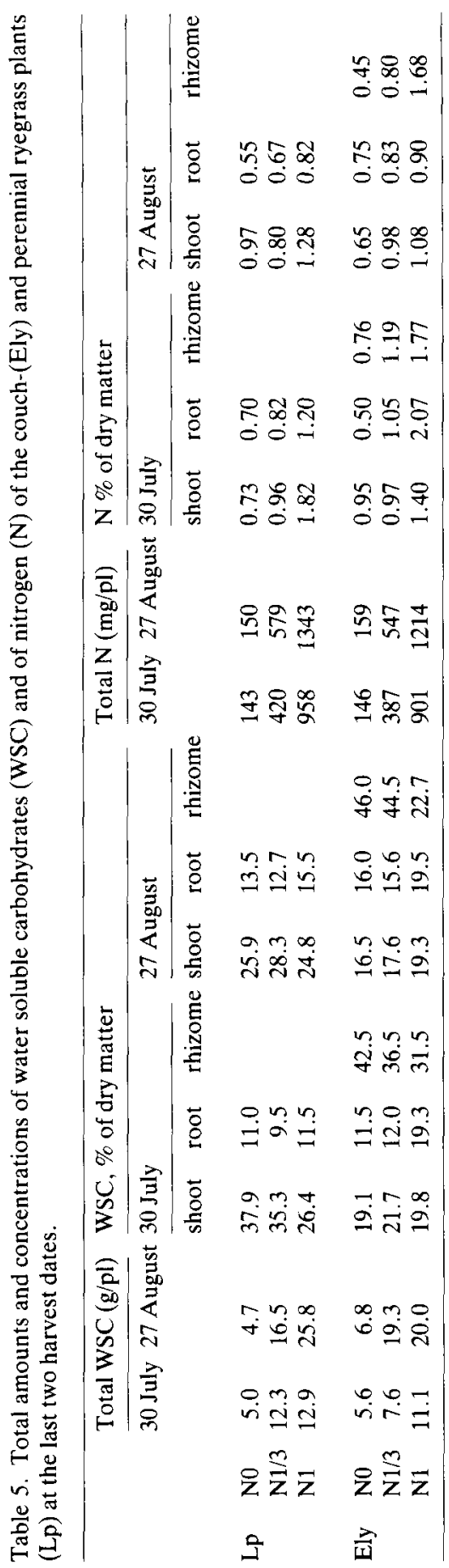

Netherlands Journal of Agricultural Science 33 (1985) 


\section{J. H. NEUTEBOOM AND W. CRAMER}
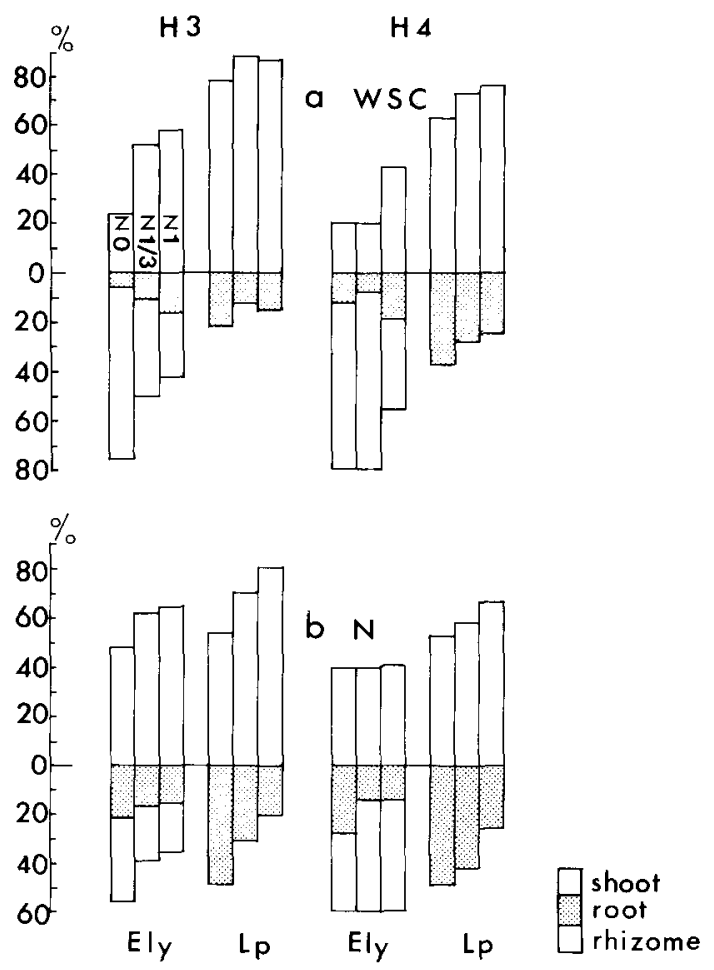

Fig. 3. Proportional distribution of water-soluble carbohydrates (WSC) (a)) and nitrogen ( $\mathrm{N}$ b)) within the couch (Ely) and perennial ryegrass (Lp) plants. Data according to the three levels of mineral supply $(\mathrm{N} 0, \mathrm{~N} 1 / 3, \mathrm{~N} 1)$ at the last two harvest dates $(\mathrm{H} 3, \mathrm{H} 4)$.

\section{Discussion}

Although couch and perennial ryegrass had comparable total relative growth rates, during the period of strong rhizome development of couch the relative growth rates of its roots and shoots decreased faster than those of perennial ryegrass. However, the relative growth rates of the roots of couch decreased more strongly: this was particularly so at the lower levels of nutrient supply. The reason for this becomes clear if we consider once more the effects that lowering of the nutrient supply had on the growth of the roots and shoots of the couch and perennial ryegrass plants. For, as follows from Fig. 2, within the range N1-N1/3 in perennial ryegrass the reduction of the nutrient supply resulted in a reduction of its shoot growth only and thus in a relative increase in the growth of its roots, whereas in couch within the same range the growth of both shoots and roots clearly decreased. Fig. 4a further shows that the root production of perennial ryegrass had increased relatively as $\mathrm{N}$ decreased, whereas root production of couch remained relatively unchanged. After the first harvest date couch also had a lower above-ground/below-ground ratio than 

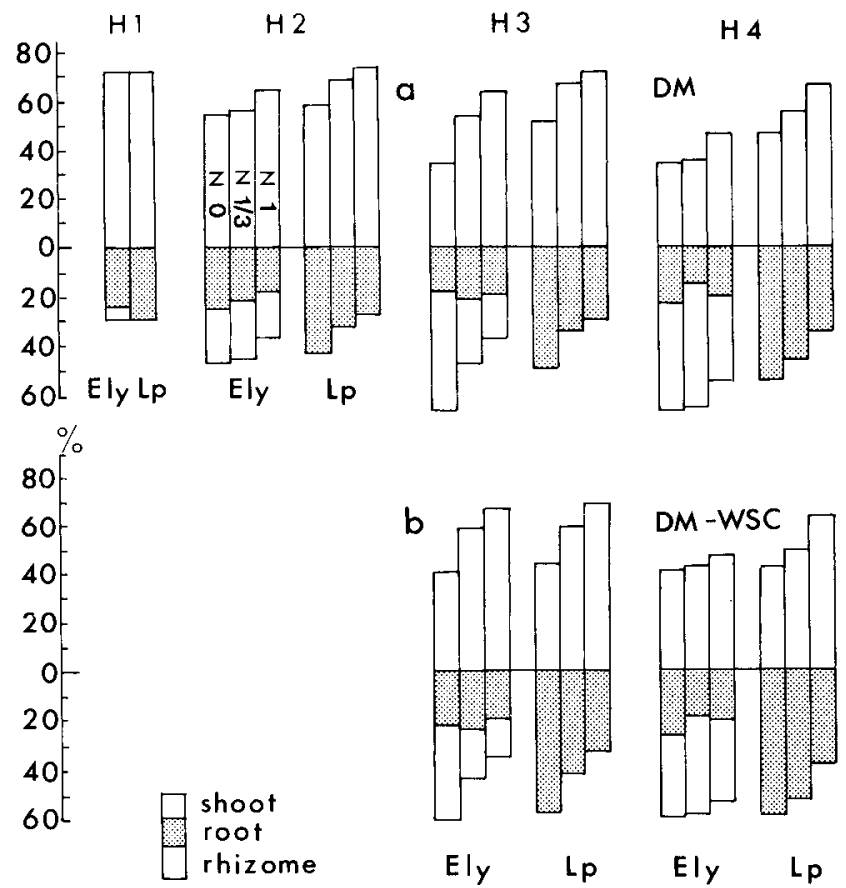

Fig. 4. Proportional distribution of the dry matter (DM (a)) and of dry matter minus water-soluble carbohydrates (DM-WSC (b)) within the couch (Ely) and perennial ryegrass (Lp) plants. Data according to the three levels of mineral supply (N0, N1/3, N1) at consecutive harvest dates $\left(\mathrm{H}_{1}, \mathrm{H}_{2}, \mathrm{H}_{3}, \mathrm{H}_{4}\right)$.

perennial ryegrass (Fig. 4a), as was to be expected from the also more strongly decreased relative growth rates of its shoots (Fig. 2). However, in the first instance this can be attributed to the difference between the species in the storage of WSC (Table 5; Fig. 3a). At the third harvest date, couch and perennial ryegrass had the same above-ground/below-ground ratio on the basis of dry matter minus WSC, as illustrated in Fig. 4b.

Not surprisingly, in vegetative perennial ryegrass at a low nutrient supply, the contribution from the roots to the dry matter increased at the expense of that from the shoots. Brouwer (1963) invoked competition for minerals between the roots and shoots to explain this, assuming that when mineral supply is limited the greater part of the minerals taken up is used by the roots. The distribution of nitrogen within the perennial ryegrass plants (Fig. 3b) is evidence to support this hypothesis.

Couch roots showed a smaller increase in the proportion of $\mathrm{N}$ at low nutrient levels (Fig. 3b). The reason that root growth of couch generally lagged behind and did not proportionally increase at low N (Fig. 4b), may have been that the rhizomes deprived the roots of carbohydrates. Carbohydrates seem to accumulate easily in rhizomes (Fig. 3a), where they can be used for rhizome growth as well as stored as reserves. Rhizomes could also act as a strong sink for nitrogen and, depending on the number of growing rhizomes and on meristem activity of lateral rhizome buds, they 
might even deprive shoots of nitrogen. This might have occurred at the last harvest, when also at the highest nutrient level the proportion of $\mathrm{N}$ in the shoots of couch had strongly decreased (Fig. 3b). At this level, couch then also had a significantly lower proportion of dry weight in the shoot than perennial ryegrass (Fig. 4). Lambers (1983), however, doubts whether competition for growth factors such as carbohydrates and minerals, is the real mechanism behind the dry matter distribution within the plant.

Unlike the perennial ryegrass plants, the couch plants had formed inflorescences; according to Friend (1966) and Troughton (1966, 1978) flower culm formation may proceed at the expense of the roots. However, such an inhibiting effect on root growth is usually accompanied by an invigorated shoot growth. In our experiment, couch did not increase its above-ground/below-ground ratio vis-à-vis the perennial ryegrass (Fig. 4). Also, the more strongly inhibited root growth of couch at lower $\mathrm{N}$ cannot be explained by flower culm formation, because there was no difference in its date of flowering or in the percentages of ear-bearing shoots between nutrient levels.

There is a similarity between our observations and those of Tietema (1981) on the growth and dry matter distribution of Carex arenaria L. In experiments on nutrient solution, Tietema found that at a constant light intensity in plant systems with widely varying weight ratios of shoots, roots and rhizomes, the relative amount of assimilates exported from the shoots to the non-assimilating plant parts was the same. This suggests that the roots and rhizomes together determine the further partitioning of these carbohydrates and thus supports the possibility of there being a special relationship between root and rhizome growth. From field experiments with potato, Harris (1982) found indications that also strong tuber growth can inhibit root growth. The potato tuber is in fact a modified rhizome which could act as a dominant sink for carbohydrates and for nutrients. According to Harris, an early cessation of the root growth can induce an early senescence of the leaf and could therefore be one of the reasons for the potato plant's inability to exploit the whole growing season for tuber production. It would be interesting to investigate if other species with strong rhizome formation also tend to neglect root growth, especially under poor soil conditions.

Nutrient supply did not stimulate total plant production in couch more than in perennial ryegrass, but in some cases it could keep the generally lower root production of couch nearer to the level of root production of perennial ryegrass. On the other hand, it may be that couch's root production is also relatively sensitive to the lower light intensities that may be expected in the faster-growing crops at a high nitrogen fertilization in grassland. Furthermore other plant characters will affect the competition between couch and perennial ryegrass in grassland. The significance of each of these characters needs to be investigated in relation to harvest regime, treading and other factors affecting the growth of plant species in grassland. In any case, at the end of the earlier mentioned competition experiment at $300 \mathrm{~kg} \mathrm{~N} \mathrm{ha}^{-1}$ year $^{-1}$ (Neuteboom, 1981), couch had not increased in closed perennial ryegrass swards at late 6-weekly mowing. Thus the beginning of a strong spread of couch in grassland is still possibly an open sward. However, the boost to rhizome branching 
which was induced by the mineral supply and which occurred prior to an increase in the rhizome dry weight, suggests that the further filling up of open patches by couch could strongly depend on the soil fertility and thus be directly related to the rate of fertilizer applications in grassland. A faster colonization of open patches by couch in intensively used grasslands agrees with the general observation that in these grasslands couch grows more in typically closed patterns than in poor grasslands (Hoogerkamp, 1975b). As couch clones can differ greatly in rhizome branching and vegetative propagation (Neuteboom, 1975), intensive grassland production might even change the couch populations in grassland in favour of the more aggressive clones.

\section{References}

Anonymous, 1981. Beschrijvende rassenlijst voor landbouwgewassen. Leiter-Nypels, Maastricht, Netherlands.

Boxem, $\mathrm{Tj}$., 1966. Geeft intensieve graslandexploitatie meer kweek? Landbouwvoorlichting 23: 319-323.

Brouwer, R., 1963. Some aspects of the equilibrium between overground and underground plant parts. Mededeling IBS No 213, p. 31-39.

Friend, D. J. C., 1966. The effects of light and temperature on the growth of cereals. In: F. L. Milthorpe \& J. D. Ivens (Eds.), Cereals and grasses. London, Butterworth.

Harris, P. M., 1982. The use of root data in some agronomic research. Root ecology and its practical application. International Symposium, Irdning.

Hoogerkamp, M., 1975a Elytrigia repens and its control in leys. EWRS Proceedings of the Symposium Status, biology and control of grassweeds in Europe, p. 322-329.

Hoogerkamp, M., 1975b. Kweek en kweekbestrijding in grasland. Gestencilde mededeling IBS, Wageningen, $84 \mathrm{pp}$.

Lambers, H., 1983. 'The functional equilibrium', nibbling on the edges of a paradigm. Netherlands Journal of Agricultural Science 31: 305-311.

Neuteboom, J. H., 1975. Variability of Elytrigia repens (L.) Desv. (Syn. Agropyron repens (L.) P.B.) on Dutch agricultural soils. Mededelingen Landbouwhogeschool Wageningen 75-7,29 pp.

Neuteboom, J. H., 1981. Effect of different moving regimes on the growth and development of four clones of couch (Elytrigia repens (L.) Desv.; Syn. Agropyron repens (L.) Beauv.) in monocultures and in mixtures with perennial ryegrass (Lolium perenne L.). Mededelingen Landbouwhogeschool, Wageningen $81-15,26 \mathrm{pp}$.

Pooswang, W., P. A. Huxley \& W. R. Buckley, 1972. Differences in growth of four clones of Agropyron repens (L.) Beauv. Proceedings 11th British Weed Control Conference: 38-45.

Tietema, T., 1981. Ecophysiology of the sand sedge Carex arenaria L. Thesis, State University of Utrecht.

Troughton, A., 1966. Further studies on the relationship between shoot and root systems of grasses. Journal of the British Grassland Society 15 (1) 41-47.

Troughton, A., 1977. Relationship between the root and shoot systems of grasses. The Belowground Ecosystem Colorado (Marshall, I.K.), Science Series No 26.

Troughton, A., 1978. The influence of reproductive development upon the root system of perennial ryegrass and some effects upon herbage production. Journal of Agricultural Science, Cambridge 91: $427-431$.

Turner, D. J., 1968. The response to defoliation of different strains of Agropyron repens and Agrostis gigantea. Proceedings 9th British Weed Control Conference: 149-155.

Wetzel, M., 1966. Zum Problem der Quecke (Agropyron repens P.B.) auf intensiv bewirtschaftetem Grünland. Das Wirtschaftseigene Futter 12: 43-56.

Williams, E. D., 1971. Effects of light intensity, photoperiod and nitrogen on the growth of seedlings of Agropyron repens (L.) Beauv, and Agrostis gigantea Roth. Weed Research 11: 159-170. 